\title{
Knowledge sharing in collaborative new product development: a study of grey box supplier involvement configuration
}

\author{
Matheus Kleber ${ }^{\mathrm{a}}$ (D), Néstor Fabián Ayala ${ }^{\mathrm{b}}$ (D), Marie-Anne Le Dain ${ }^{\mathrm{C}}$ (D) Érico Marcon $^{\mathrm{b}}$ (D), \\ Alejandro Germán Frank ${ }^{\mathrm{b} *}$ \\ ${ }^{\mathrm{a} A G C O}$ Corp, Canoas, RS, Brasil

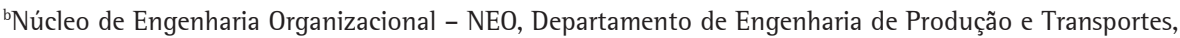 \\ Universidade Federal do Rio Grande do Sul - UFRGS, Porto Alegre, RS, Brasil \\ 'Grenoble INP - G-SCOP, Grenoble, France \\ *frank@producao.ufrgs.br
}

\begin{abstract}
Paper aims: To shed light on how knowledge is shared between companies during a collaborative new product development (NPD) process.

Originality: It is the first study of different knowledge sharing levels for each stage of the NPD process in an inter-organizational context.

Research method: A research framework was created based on the literature. Guided by this framework, an in-depth case study was performed in a multinational company analyzing the knowledge sharing with the company's supplier during a collaborative NPD process.
\end{abstract}

Main findings: Different levels of knowledge sharing were found at each stage of the NPD process.

Implications for theory and practice: The results complement previous works demonstrating that this phenomenon should not be considered as a binary state. By clearly presenting how knowledge sharing occurs at each phase of the NPD process, managers can be prepared and correctly implement tools to support NPD teams from both buyer and supplier companies.

Keywords

New product development. Knowledge management. Knowledge sharing. Supplier involvement. Grey box.

How to cite this article: Kleber M, Ayala NF, Le Dain MA, Marcon E, Frank AG. (2019). Knowledge sharing in collaborative new product development: a study of grey box supplier involvement configuration. Production, v. 29 , e20180071. https://doi.org/10.1590/0103-6513.20180070

Received: Sept. 05, 2018; Accepted: Nov. 27, 2018.

\section{Introduction}

Knowledge management is not an easy task for organizations (Gonzalez \& Martins, 2015). When knowledge needs to flow between different organizations the barrier is even harder to overcome. Several studies were developed to understand how knowledge sharing should happen between organizations when it is necessary to develop a product or service in collaboration (Frank et al., 2013; Laursen \& Andersen, 2016; Ramadhan \& Samadhi, 2016). Several authors have studied how to integrate suppliers in the New Product Development (NPD) process and how knowledge sharing within the supply chain can add value to a company to the buyer by improving products and processes (Büyüközkan \& Arsenyan, 2012; Frank \& Echeveste, 2012; Frank \& Ribeiro, 2014; Le Dain \& Merminod, 2014; Samuel et al., 2011; Yoo et al., 2015). However, extant authors have considered the knowledge sharing in collaborative NPD as a singular process, as if throughout the whole 
product development process the level of the knowledge shared was the same (e.g. Ayala et al., 2017; Le Dain \& Merminod, 2014). Because of this, there is a lack of clarity on how the knowledge sharing permeates the product development process among different organizations.

By the extend of our knowledge, no authors have clearly presented how knowledge sharing occurs during each NPD phase. Aiming to fulfill this gap in knowledge, this study seeks to answer the following research question: how does it occurs the knowledge sharing between the buyer company and its suppliers during a collaborative NPD project? For this sake, an in deep case study is presented from a company that follows a structured NPD methodology, where it was possible to collect data and interviews about collaborative projects seeking to identify the best practices that maximize the success of the collaborative product development.

As results, this study shows in detail how knowledge sharing occurs, and with which intensity, during each phase of an NPD project (Cooper, 1990). Complementing prior researches that have studied collaborative NPD (e.g. Le Dain \& Merminod, 2014), this study demonstrates that knowledge sharing is not a binary process and that throughout the NPD phases, within the same supplier collaboration type, there are different levels of knowledge sharing. These results can also support companies to identify and optimize sharing moments during the NPD in the supplier collaboration perspective, creating mechanisms to facilitate knowledge sharing between both agents.

\section{Theoretical background}

\subsection{New product development process}

NPD is a sequence of activities developed by a company to develop and commercialize products (Ulrich \& Eppinger, 1995). There are several theoretical models that, generally, are a guide of sequenced activities seeking to conduce product development. A well-known one is the Stage Gates ${ }^{\circledR}$ model introduced by Cooper (1990, 1993). This model is composed by phases and systematic verifications, aiming to guarantee that the development of a product reaches the minimum requirements for a project continuity. Cooper's (1990) model is divided into five phases with defined decision moments from the idea generation to the product launch. This model comprehends several deliverables, that are a set of activities that must be completed during each development phase. At the end of each phase, the company must organize an evaluation committee with the objective of deciding about aspects of the progress of the product developed. This moment is called gate.

As observed in Figure 1, in Cooper's (1990) model, after the idea generation, there is a screening to check the idea's adherence to the company's objectives. This phase is named Discovery. After the initial screen, the project goes through the first gate for a moderate analysis of market attractiveness, technical feasibility, strategic alignment and other eliminating variables such as legal issues or environmental requirements. The project enters the first phase if approved in Gate 1, which is named Scoping. In this moment, a superficial analysis covering the project's schedule, estimated costs, market potential, costs and the technology involved and thus, the project is sent to the second gate. If approved in Gate 2, the project goes to the Business Plan Case phase. During this phase, the business case of the project is developed, defining the product's concept, marketing mix, market

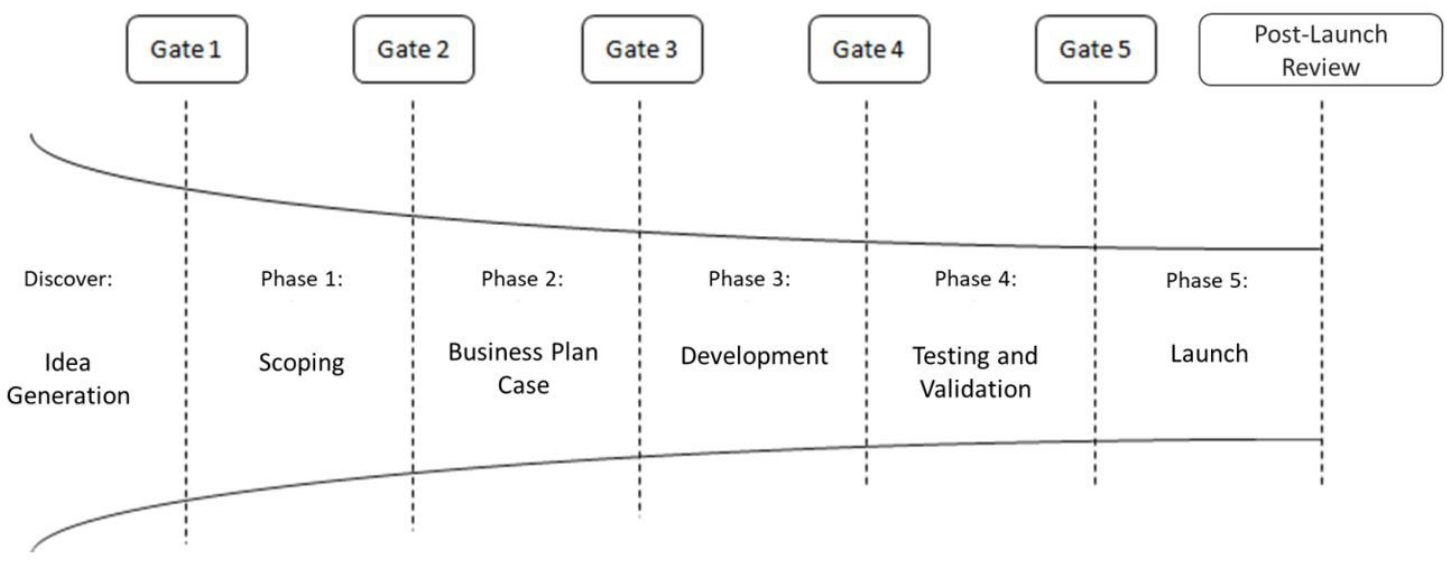

Figure 1. Theoretical model for product development. Source: Adapted from Cooper (1990). 
requirements and the project's technical feasibility, translating the customer's needs into a technical conceptual solution. At the end of this phase, the project goes through Gate 3, an analysis of the economic feasibility, and if approved, the project enters the third phase, called Development. This phase comprehends the production of a laboratory prototype for customer's feedback, elaboration of a tests plan and the production plan. After this phase, the project goes through Gate 4. The next phase is called Testing and Validation, in which extensive laboratory tests and customers evaluations are performed. The Testing and Validation also evaluates the operations and production in a pilot scale. After this phase, during Gate 5, the project enters into the Launch phase. During this phase, production and operations achieve a larger scale and the marketing plans are executed. Finally, Cooper (1990) indicates that, at the end of the NPD, a Post Launch Review must be carried out, in order to measure the performance of the product under technical and economic aspects and also to dissolve the project team, formalizing the passage of the project to a "regular product" status into the organization.

\subsection{Knowledge sharing in NPD}

Knowledge sharing with external suppliers is a key factor for the NDP success (Petersen et al., 2005; Frank et al., 2014; Ayala et al., 2017; 2018; Enrique et al., 2018). Many authors contributed in expanding the understanding about how knowledge flows among individuals and organizations. An important study was carried out by Polanyi (1962), who shaped the basic structure on knowledge management through the comprehension that individuals have different types of knowledge, explicit or tacit, which are acquired through different forms. Nonaka \& Takeuchi (1995) build on this initial definition creating a model for the conversion of knowledge that consists of four stages that continuously repeat, increasing the knowledge in the organization. Posteriorly, authors like Davenport \& Prusak (1998) and Argote \& Ingram (2000) provided a consolidated vision on what today is understood as the knowledge sharing process. In this sense, knowledge sharing and transfer are mostly considered as synonyms (Frank \& Ribeiro, 2014) and are considered as a process of moving both type of knowledge, tacit and explicit, from a project team (source) to another team (recipient) and its subsequent absorption and reusing in new products and technologies to improve the overall performance of NPD (Frank et al., 2013; Frank \& Echeveste, 2012). This view considers that knowledge sharing in NPD is composed at least by the following elements: i) a source and a recipient of the knowledge that will be shared (Argote \& Ingram, 2000); ii) a content or knowledge types to be shared (Frank \& Ribeiro, 2014); and iii) a channel through which knowledge will be shared, which can be informal by face-to-face interactions, for example, or by formal way as for instance through information technologies (Alavi \& Leidner, 2001).

In this work, we adopt the knowledge sharing model proposed by Carlile (2004), which has been already used in prior research for the study of knowledge sharing with suppliers (e.g. Le Dain \& Merminod, 2014; Ayala et al., 2017). Carlile (2004) proposes a model for the knowledge sharing analysis, encompassing different boundaries to overcome, when people and organizations intend to share knowledge. Differently from the traditional view, Carlile (2004) proposes that, depending on the work's purpose, knowledge sharing can be easier or harder to be shared. Therefore, the author divides knowledge sharing it into three layers: pragmatic, semantic and syntactic. The syntactic layer refers to basic knowledge sharing, when both the involved agents know about the subject and can easily establish a communication because the language and technical terms are common for the involved parties. When different agents are sharing knowledge in the syntactic layer, Carlile (2004) calls such process knowledge transfer. Generally, knowledge transfer can be done and comprehended through simple documents, technical specifications, drawings or e-mails (Ayala et al., 2017; Carlile, 2004; Le Dain \& Merminod, 2014). The semantic layer is the second in terms of complexity. lt represents the barrier of sharing knowledge that happens due to the lack of communication clarity or ambiguous meanings that can exist between different agents. Knowledge sharing under such conditions occurs when e-mails, data or phone calls are not enough for agents to comprehend one another, and meetings or more extended explanations are necessary for avoiding misunderstandings (Ayala et al., 2017; Carlile, 2004; Le Dain \& Merminod, 2014). Knowledge sharing in such conditions is called translation.

Finally, the last and most complex layer of communication is called pragmatic. In this level, there is no ready solution that can explained to the interlocutor. In this case, both agents need to jointly seek a solution for complex problems that meet the interests of both parties (Ayala et al., 2017; Carlile, 2004; Le Dain \& Merminod, 2014). When knowledge is shared in such aspects, it is said that a knowledge transformation happened. Due to each of the knowledge sharing forms start with the letter T (Transfer, Translation and Transformation) the model of Carlile (2004) is also known as the 3-T model.

This study considers the model of Carlile (2004) for knowledge sharing in the following sections due to its broadness, separating knowledge sharing into complexity levels and due to its synergy with the study of Le Dain 
\& Merminod (2014), who carried out a research identifying the levels of supplier collaboration and knowledge sharing, as following exposed.

\subsection{Collaboration between organizations}

Considering the increasing need of multidisciplinary knowledge for the successful of NPD, there is a growing need of collaboration both internally and externally (Enrique et al., 2018). As stated by Enrique et al. (2018), external partnership includes several distinct actors, such as customers, suppliers, universities and research institutes, and even competitors, being suppliers and customers are the most common ones. The literature on participatory design and co-creation has been dedicated to study the mechanisms and ways such collaboration can results in innovation for NPD (Broberg \& Conceição, 2017; Sinkovics et al., 2018). This literature has shown that different forms of collaboration may have significant impact on product performance (Bodas Freitas \& Fontana, 2018).

In this paper, we focus specifically on the stream of research which considers the modes of interaction a company can establishes with its suppliers for NPD activities. According to the level of supplier's involvement, Petersen et al. (2005) argue that three configurations can be found in NPD projects involving suppliers and buyers: (i) White Box (design is buyer-driven), (ii) Grey Box (joint design) and (iii) Black Box (design is supplier-driven). Following this reasoning, Le Dain \& Merminod (2014) developed three propositions to identify how knowledge sharing, between the firm and the supplier, occurs during NPD. The propositions of Le Dain \& Merminod (2014) are: (i) white box, which mainly consists on knowledge transfer; (ii) Grey box, which require high knowledge transfer, translation and transformation; (iii) Black box, which demand high knowledge transfer and substantial translation during design phases. With results of a research encompassing two companies, Le Dain \& Merminod (2014) indicate that the configurations of the white box type consist of a medium level of knowledge transfer, however, potentially, the translation of knowledge among agents can be necessary. In collaboration cases of the grey box type, knowledge transference, translations and transformation were high. Finally, the analysis in the collaboration cases of the black box type indicated that there is a high transference and translation of knowledge, however it cannot be ignored that there is also knowledge transformation in this configuration, in cases of solving complex problems. Grey box projects are the focus of the present study since it is a rare and complex configuration, given the intense necessity for collaboration.

It can be seen in the work of Le Dain \& Merminod (2014) a relevant view about how knowledge sharing occurs in different configurations, however it is not clear how it happens during the NPD phases. Additionally, some propositions in the authors' studies are partially corroborated by the field research, which gives room for interpretations. The objective of this study is to present, in an organized way, how knowledge sharing occurs during each of the NPD phases in a joint development process, i.e. Grey Box. This specific buyer-supplier configuration was selected because was the one that presented higher complexity and intensity of knowledge sharing in Le Dain \& Merminod's (2014) study.

\section{Research method}

\subsection{Framework for the knowledge sharing levels during NPD phases}

Through the theoretical concepts above stated, the research framework presented in Figure 2 was developed to guide the case study and the analysis of the data collected in the organization studied. The framework's objective is to make possible to visualize and measure the knowledge sharing in each of the three levels presented by Carlile (2004), in the 3-T model, through each of the NPD phases, according to Cooper's (1990) Stage Gates ${ }^{\circledR}$ model. Therefore, we used a scale similar to the one proposed by Le Dain \& Merminod (2014), which measures the level of the knowledge shared with suppliers in collaborative projects.

Le Dain \& Merminod (2014) list sixty documents and deliverables that evidence the occurrence of the most basic level of knowledge sharing: knowledge transfer. This set of documents that shows the knowledge transfer are called Boundary Objects (Le Dain \& Merminod, 2014). The authors also present eight situations that knowledge translation occurs, mainly defined as situations to avoid sticky knowledge glitches in the NPD. Finally, Le Dain \& Merminod (2014) present four situations that evidences the knowledge transformation that can happen during the NPD and present the highest knowledge sharing level. These are high complexity problem solving situations.

In this study, the knowledge sharing intensity during each of the situations analyzed was divided into five levels, as depicted in Table 1, according to the maturity and the level of involvement of the company studied with its supplier. Each of the sixty boundary objects, eight knowledge translation opportunity and four knowledge 


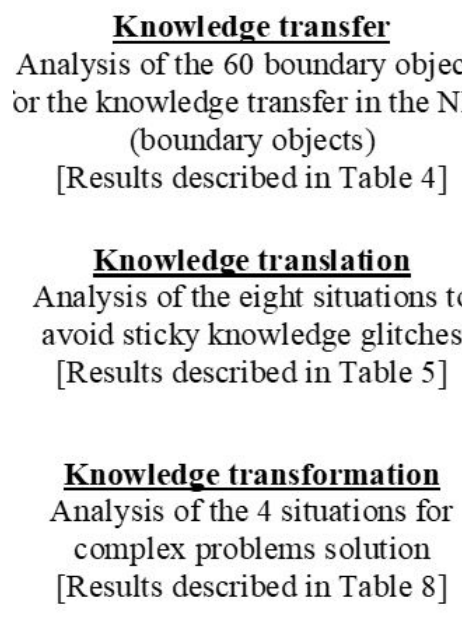

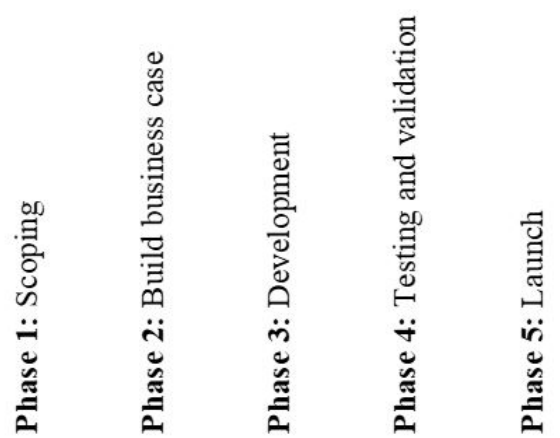

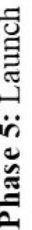

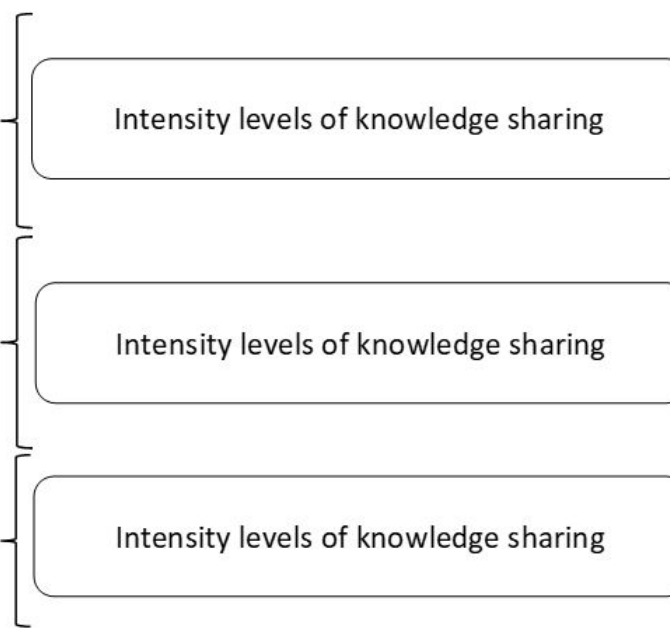

Figure 2. Research framework.

Table 1. Knowledge sharing levels.

Intensity levels of knowledge sharing

Absent: No evidence of knowledge sharing with supplier was found in the case studied for this subject. No interaction.

Low interaction: Happens when the object of study is ongoing and the main decisions that affect the business of both companies have been already taken. There is just the need to follow the activities at an operational level to guarantee that they are being developed as initially planned. The contact between the companies can be frequent, however the knowledge exchanged is restricted to simple information exchange with low impact on the project's conduction.

Medium interaction: level of detailing, complexity and information accuracy for the object of study goes beyond a simple follow up of the progress of the activities, however, the decisions about the object of study that can affect the companies' business were already made between the companies. The progress demands, in this case a review of the information provided regarding the increased maturity of the project.

High interaction: Occurs when there is a necessity to build a solution from scratch for a given object of study. Despite the need for a low level of detailing, there is a high company-supplier interaction, in order to break the inertia between the teams of supplier's company client, as a means to present a plausible solution for both companies.

Very high interaction: This is the highest level of company-supplier interaction since it is reserved for contract signings or agreements that affect the continuity or the feasibility of the project or the business of one of the companies. This level also represents the final versions of the objects of study that demand a high level of commitment between both companies or, finally, the review/ development of prototypes, physical or virtual that demand great collaboration between companies.

transformation opportunities were analyzed during each phase of the NPD. The knowledge sharing intensity levels were classified as Absent; Low interaction; Medium interaction; High interaction and Very high interaction.

\subsection{Research procedures}

For the conduction of this research an empirical case study was carried out with qualitative data collection due to its better fit to the study's objective, as proposed by Voss et al. (2002), who highlight that when the objective is to check a theory's generalization, a case study must be conducted to validate and deeply examine the data 
of empirical results. A single case was selected to describe, in details, the knowledge sharing phenomenon in a collaborative project. Therefore, this study has an applied nature and qualitative approach since it seeks to better comprehend the buyer-supplier knowledge sharing processes throughout the NPD. The research procedures were based on Voss et al. (2002) stages which consists in: (i) Case study selection; (ii) Development of the research instruments; (iii) Data collection and (iv) Data analysis and validation. Next, we describe these stages.

\subsection{Case study selection}

The case study was selected through a theoretical sampling (Voss et al., 2002). Eisenhardt \& Graebner (2007) indicate that a theoretical sampling approach designates the selection of a case study according to its fitness to solve the problem studied. For this study, a company that meets three basic requirements was sought. First, the company should have a structured NPD in which was possible to corelate theoretical models with the company's practice. Second, the company should have at least one project of supplier collaboration in the grey box level, it means, the company should have been developing a product together a supplier, in a case where, without the supplier collaboration, the product would not be successfully developed. Finally, the company should be willing to provide details of the project for the researchers, to allow analysis and measurement of the intensity of the buyer-supplier knowledge sharing.

The selected organization is a North American based multinational company, with operations in more than one hundred and forty countries and develops agricultural solutions such as tractors, harvesters and agricultural implements. The interviews were conducted in Brazil, where the company has more than one thousand local and international suppliers, and, during this study's conduction, more than sixty simultaneous NPD projects. To ensure anonymity, the company will be called Company A.

Among more than sixty ongoing NPD projects in Company A, only one met the criteria of a grey box project. The chosen project was the development of tractor cabin. The project is considered by the company as an incremental innovation, since the cabin follow the general concept of cabins but it comprises innovative components that provides strategic differentiation in the market. The project was characterized as grey box, due to restrictions in the manufacturing processes, logistics and supply chain the Company A was not able to conduce the project by itself. The cabin was an innovation for a specific market, where Company A wanted to increase its market share. The whole product development engineering was done together with the chosen supplier to develop the project and manufacture the cabin. Since both companies partnered to develop the product project and needed to transfer, translate and transform knowledge, this was the project chosen to conduct the following analysis.

Regarding the NPD project background, among all projects presented to the researchers during the interviews in Company A, the project for the development of a tractor cabin encompassed a pure example of a grey box collaborative project. This project required the direct involvement of several sectors from both Company A and the supplier. Both companies had to share information between several areas throughout the entire project development process.

The supplier chosen by Company A to partner in the development of the cabin is an American multinational enterprise that holds a manufacturing operation in Brazil in a different state from the manufacturing site of Company A. The geographical difficulty highlighted specific points which will be reported in the data analysis section, such as the need for in-person meetings to discuss critical topics and solution to high complexity problems.

The decision for the supplier for the collaborative development project essentially considered three factors that are common to grey box, white box, and black box project, in addition to the technological domain of cabin manufacture, which intended to complement Company A's competences. Common criteria were: 1) cost competitiveness; 2) analysis of the quality history of the product supplied; 3) supplier's capability to manufacture the product. As exposed in the interviews, these factors differentiated the grey box project for Company A. According to the employees interviewed, in white and black box projects, supplier assessment considers similar criteria, nevertheless, diligence levels with suppliers are reduced, less detailed and less bureaucratic when compared to the selection of this supplier, since it involved strategic levels of Company A.

Cabin development was a complex project for the Company A in supply chain and strategic terms, since no companies with the size of Company A supplied products with the required specifications for the Brazilian low horse-power tractors market segment. "We had a portfolio gap because we did not have any version of our product with a cabin for this segment and it was an old market demand" (Project specialist 2). According to the participants, the decision for a grey box project mainly derived from basically the manufacturing capabilities of Company A, the reduced time to market when compared to developing the project alone, and complementary knowledge detained by both companies about the development process of agricultural machine components, 
which enabled the creation of new knowledge (transformation) during the NPD. This type of project requires such high level of collaboration that it was informally called "the four-hands project" inside Company A (Engineer 1).

\subsection{Research instruments}

According to Voss et al. (2002) suggestions for the case study stages, after the researchers selected the case, they should define the appropriate research instruments for the empirical investigation, namely data collection. As the source of applied information, semi structured interviews were conducted with employees from Company A with the aim to clarify the levels of knowledge sharing during each phase of the NPD, based on the framework proposed in Figure 1. Participants were asked to provide practical examples that justified their answers regarding the interaction level with the supplier for the conduction a product development project. This aimed at identifying a grey box project inside the organization and details that would enable measuring the intensity of each knowledge sharing type level. The initial version of the interview protocol was designed by a team of researchers, who are member of a study group from a Brazilian university, with the aim to group similar demands from the researchers. After the structure of the interviews was validated, eight employees from company A were additionally interviewed in person. Thus, a total of nine interviews with employees from three departments strongly involved in the collaborative project: engineering, purchases and project management.

In addition to the interviews, company A provided to the researchers documents shared or created together with the supplier during the cabin project development phases to compare the maturity level of each of the sixty boundary objects from the eight situations to avoid sticky knowledge glitches and from the four complex problem resolution situations, with the aim to answer possible doubts or inconsistencies found in the model. Afterwards, a second round of interviews with the employees of Company A was conducted to deepen the understanding of knowledge sharing with suppliers. Researchers and employees exchanged emails until a complete understanding was reached regarding the extent of knowledge sharing intensity involved in each situation (sixty boundary objects, eight knowledge translation opportunities, and four knowledge transformation opportunities) in each NPD phase.

After each participant explained how knowledge sharing occurred, they assessed the intensity level of knowledge sharing in a five-point scale shown in Table 2, which was inspired in Le Dain \& Merminod (2014). The scale represents: $0=$ no interaction; $1=$ low interaction; $2=$ medium interaction; $3=$ high interaction; $4=$ very high interaction. The scale was proposed to identify the increase in supplier interaction for each type of knowledge sharing. The progressive numeric scale grows together with the increase in the supplier involvement level. During the interviews, through examples, each participant identified the maturity level of each delivery and the level of involvement between Company $A$ and the supplier at each step of the project. The documents provided by the Company A were used to corroborate or complement the information from the interviews.

Table 2. Classification of knowledge sharing in Company A.

\begin{tabular}{ccc}
\hline Intensity level of knowledge sharing & Classification & Graphical representation \\
\hline No interaction & 0 & $\circ$ \\
Low interaction & 1 & 0 \\
Medium interaction & 2 & \\
High interaction & 3 & $\bullet$ \\
Very high interaction & 4 & $\bullet$ \\
\hline
\end{tabular}

In order to enable a quantifiable numeric analysis, a classification in ranges was established as Table 2 presents. The ranges considered the level of knowledge sharing intensity between Company $A$ and its supplier in the grey box project of this study. This classification considers the information collected in the company during the interviews and the analysis of the information used by the project manager responsible for the grey box project development of the cabin. The range-type classification aims to translate the practical actions established between company A and the supplier during the NPD, into a numeric scale that can be understood by readers and which addresses the interaction levels between the parts during each NPD phase for the sixty boundary objects, eight knowledge translation opportunities and knowledge transformation opportunities analyzed herein. 


\subsection{Data collection}

Voss et al. (2002) suggest that in this stage researchers should take of biases results based on partial observations of the phenomena. Therefore, we used four researchers to collect data in the interviews. One of them conducted the semi structured questions, while the three others took notes of the impressions and observations. Interviews lasted on average an hour and a half and were recorded with the assistance of an audio recorder in sequence the interview records were transcribed for analysis. After the analysis of the notes from each researcher and the transcriptions, a second round of interviews was conducted with the aim to solve remaining questions. Interviews started in May 2016 and the last round of interviews to solve questions occurred in June 2017.

The interview's instrument was designed with the aim to initially allow the interviewees to talk about the product development process in the company where the case study was conducted, highlighting how the demand for the development of a new product is initiated, how project teams were established, how the NPD occurs in terms of development phases and deliverables and highlighting their functions in the process. This first part of the interview aimed to understand the company's structure and how each area was added to the NPD. Three key areas to understand supplier involvement in the NPD were considered: purchases, engineering, and project management. To ensure response consistency, three employees from each area were interviewed.

After identifying how Company A structures its NPD, respondents were asked about specific questions that addressed supplier involvement in the NPD. Specifically, participants were asked to talk about a project where: 1) Company A is the design owner of the project and a supplier is responsible for manufacturing the project; 2) the supplier is the project design owner and Company A uses such solution in one of its products; 3) Company $A$ and the supplier need to create a project solution together. We asked participants to highlight how the process occurs in each individual situation proposed, emphasizing the differences from white box, grey box, or black box, and commenting about the specific difficulties that existed in collaborative development, grey box. Table 3 presents the profile of the interviewees at this company.

Table 3. Interviewees profile.

\begin{tabular}{cc}
\hline Position of the interviewee in the company & Years of experience in the company \\
\hline Project specialist 1 & 2 \\
Project specialist 2 & 6 \\
Project manager & 6 \\
Purchase analyst 1 & 19 \\
Purchase analyst 2 & 4 \\
Purchase manager & 10 \\
Product engineer 1 & 6 \\
Product engineer 2 & 15 \\
Product engineering supervisor & 5 \\
\hline
\end{tabular}

\subsection{Data analysis and validation}

The last stage proposed by Voss et al. (2002) is the validation. The validation of the results considered the interviews conducted with nine participants. The interviews considered the same set of questions which were conducted as a semi-structured report to assure response consistency. In addition to the information collected in the interviews, multiple sources of evidences were made available by Company A to validate the existence or not of each one of the sixty boundary objects, eight knowledge translation opportunities, and four knowledge transformation opportunities proposed by Le Dain \& Merminod (2014). Authors were granted access to documents, emails, and internal procedures of Company A from the project's document repository with the aim to define knowledge sharing level in each NPD phase, following knowledge sharing levels established in Figure 2.

In the knowledge transfer analysis, project deliverables registers were analyzed into the companies' repository (Company A's computer network and intranet), which served as evidences of the maturity evolution for each project deliverables. At times, documents used by Company A was so complex and rich in information that it encompassed two or more knowledge transfers, based on Le Dain \& Merminod (2014). In these cases, two or more boundary objects were shared between Company A and its supplier, although it occurred in a single document.

To validate the existence and the evolution of the knowledge sharing maturity of the translation and transformation types, in addition to the documents made available, the responses from the interviews were 
considered, since the resolution to complex problems (knowledge transformation) or the solution to questions, misunderstandings, or interpretation mistakes (knowledge translation) were not always recorded as project deliverables in NPD phases. Thus, the interviews were crucial for the results.

\section{Results}

This section aims to provide an analysis of each form of knowledge sharing, encompassing the whole project with the aim to detail how each situation of knowledge sharing occurs during each phase and in which intensity level.

\subsection{Knowledge transfer}

The average knowledge transfer measured by the sixty boundary objects proposed by Le Dain \& Merminod (2014) were evaluated in Company A and 55 boundary objects of the theoretical model were found on the case studied. The detailed results of each NPD phase are shown in Table 4, which follows the same graphical representation proposed in Table 2.

Table 4. Boundary objects analysis.

\begin{tabular}{|c|c|c|c|c|c|c|c|}
\hline & $\begin{array}{l}\text { List of the boundary } \\
\text { objects: } \\
\text { Knowledge transfer }\end{array}$ & $\begin{array}{l}\text { Phase 1: } \\
\text { Scoping }\end{array}$ & $\begin{array}{l}\text { Phase } 2 \text { : Build } \\
\text { business case }\end{array}$ & $\begin{array}{l}\text { Phase 3: } \\
\text { Development }\end{array}$ & $\begin{array}{l}\text { Phase 4: } \\
\text { Testing and } \\
\text { validation }\end{array}$ & $\begin{array}{l}\text { Phase 5: } \\
\text { Launch }\end{array}$ & $\begin{array}{l}\text { Post-Launch } \\
\text { Review }\end{array}$ \\
\hline 1 & $\begin{array}{l}\text { After sales service first } \\
\text { reports }\end{array}$ & $\circ$ & $\circ$ & $\circ$ & $\circ$ & $\circ$ & $\bullet$ \\
\hline 2 & After sales service plan & $\circ$ & $\boldsymbol{\bullet}$ & $\bullet$ & - & $\circ$ & ० \\
\hline 3 & $\begin{array}{l}\text { After sales services bill of } \\
\text { material }\end{array}$ & $\circ$ & - & $\bullet$ & 0 & ○ & $\circ$ \\
\hline 4 & Contract with the supplier & $\bullet$ & $\bullet$ & $\circ$ & $\circ$ & $\circ$ & ० \\
\hline 5 & Control range optimization & \multicolumn{6}{|c|}{ No evidence found } \\
\hline 6 & Cosmetic mock-up & $\circ$ & • & $\circ$ & $\circ$ & $\circ$ & $\circ$ \\
\hline 7 & Cost analysis & $\bullet$ & $\bullet$ & $\odot$ & $\odot$ & 0 & 0 \\
\hline 8 & $\begin{array}{l}\text { Critical Components } \\
\text { Listing }\end{array}$ & $\circ$ & $\circ$ & - & - & - & $\circ$ \\
\hline 9 & Design brief & ○ & $\bullet$ & $\circ$ & $\circ$ & $\circ$ & $\circ$ \\
\hline 10 & Drawing & ○ & $\circ$ & $\bullet$ & - & - & $\circ$ \\
\hline 11 & $\begin{array}{l}\text { First Article Inspection } \\
\text { report }\end{array}$ & $\circ$ & $\bullet$ & $\bullet$ & $\bullet$ & $\bullet$ & $\circ$ \\
\hline 12 & First tools report & \multicolumn{6}{|c|}{ No evidence found } \\
\hline 13 & Functional specifications & - & $\bullet$ & - & $\circ$ & $\circ$ & $\circ$ \\
\hline 14 & $\begin{array}{l}\text { Geographic Exclusivity } \\
\text { Agreement }\end{array}$ & \multicolumn{6}{|c|}{ No evidence found } \\
\hline 15 & $\begin{array}{l}\text { Global project } \\
\text { specifications }\end{array}$ & - & $\bullet$ & ( & ○ & $\circ$ & $\circ$ \\
\hline 16 & Homologation request & $\bullet$ & $\bullet$ & $\odot$ & $\odot$ & $\bullet$ & $\circ$ \\
\hline 17 & Industrial property analysis & $\bullet$ & - & $\bullet$ & $\circ$ & $\circ$ & $\circ$ \\
\hline 18 & Industrial specifications & $\circ$ & - & $\bullet$ & $\circ$ & $\circ$ & $\circ$ \\
\hline 19 & Industrialization plan & - & - & $\circ$ & $\circ$ & $\circ$ & $\circ$ \\
\hline 20 & $\begin{array}{l}\text { List of components from } \\
\text { 2nd tier suppliers }\end{array}$ & $\circ$ & $\bullet$ & $\bullet$ & $\circ$ & $\circ$ & $\circ$ \\
\hline 21 & Manufacturing capabilities & $\circ$ & $\circ$ & - & $\bullet$ & $\circ$ & $\circ$ \\
\hline 22 & $\begin{array}{l}\text { Manufacturing Process } \\
\text { Definition }\end{array}$ & $\circ$ & $\bullet$ & $\bullet$ & $\circ$ & $\circ$ & $\circ$ \\
\hline 23 & $\begin{array}{l}\text { Manufacturing Process } \\
\text { Implementation }\end{array}$ & $\circ$ & $\circ$ & $\bullet$ & - & - & $\circ$ \\
\hline 24 & $\begin{array}{l}\text { Marketing test reports } \\
\text { based on prototypes }\end{array}$ & $\circ$ & $\circ$ & - & 0 & 0 & $\circ$ \\
\hline 25 & Mass Production Release & ० & $\circ$ & $\circ$ & $\circ$ & $\bullet$ & $\circ$ \\
\hline 26 & Mock-up & $\circ$ & $\bullet$ & $\circ$ & $\circ$ & $\circ$ & $\circ$ \\
\hline
\end{tabular}

○ No interaction; $\bigcirc$ Low interaction; Medium interaction; $\bullet$ High interaction; Very high interaction. 
Table 4. Continued...

\begin{tabular}{|c|c|c|c|c|c|c|c|}
\hline & $\begin{array}{l}\text { List of the boundary } \\
\text { objects: } \\
\text { Knowledge transfer }\end{array}$ & $\begin{array}{l}\text { Phase 1: } \\
\text { Scoping }\end{array}$ & $\begin{array}{l}\text { Phase } 2 \text { : Build } \\
\text { business case }\end{array}$ & $\begin{array}{c}\text { Phase 3: } \\
\text { Development }\end{array}$ & $\begin{array}{l}\text { Phase 4: } \\
\text { Testing and } \\
\text { validation }\end{array}$ & $\begin{array}{l}\text { Phase 5: } \\
\text { Launch }\end{array}$ & $\begin{array}{l}\text { Post-Launch } \\
\text { Review }\end{array}$ \\
\hline 27 & Non disclosure agreement & $\circ$ & $\bullet$ & $\circ$ & $\circ$ & $\circ$ & $\circ$ \\
\hline 28 & Packaging analysis & $\circ$ & $\bullet$ & - & $\circ$ & $\circ$ & $\circ$ \\
\hline 29 & $\begin{array}{l}\text { Packaging Samples } \\
\text { Approval }\end{array}$ & $\circ$ & $\circ$ & $\circ$ & $\bullet$ & $\circ$ & $\circ$ \\
\hline 30 & Patents & 0 & - & $\bullet$ & $\circ$ & ○ & $\circ$ \\
\hline 31 & Pilot run report & $\circ$ & $\circ$ & $\circ$ & $\bullet$ & $\circ$ & $\circ$ \\
\hline 32 & Product Delivery Schedule & - & $\bullet$ & ( & ( & - & $\circ$ \\
\hline 33 & Product FMEA Report & - & 0 & ○ & $\circ$ & $\circ$ & $\circ$ \\
\hline 34 & $\begin{array}{l}\text { Product technical } \\
\text { specifications }\end{array}$ & $\bullet$ & $\bullet$ & (1) & $\circ$ & $\circ$ & $\circ$ \\
\hline 35 & $\begin{array}{l}\text { Product Verification } \\
\text { Report }\end{array}$ & $\bullet$ & $\bullet$ & ○ & $\odot$ & $\bullet$ & ० \\
\hline 36 & Project closing report & $\circ$ & $\circ$ & $\circ$ & $\circ$ & $\circ$ & $\bullet$ \\
\hline 37 & Project Data Availability & - & $\bullet$ & $\circ$ & $\circ$ & $\circ$ & $\circ$ \\
\hline 38 & $\begin{array}{l}\text { Project financial } \\
\text { commitment }\end{array}$ & $\bullet$ & $\bullet$ & - & - & - & $\circ$ \\
\hline 39 & Project planning & 0 & $\bullet$ & (1) & (1) & - & $\circ$ \\
\hline 40 & Project summary report & - & $\bullet$ & $\circ$ & $\circ$ & $\circ$ & $\circ$ \\
\hline 41 & $\begin{array}{l}\text { Prototype needs (for } \\
\text { quality, marketing...) }\end{array}$ & $\circ$ & $\bullet$ & - & - & $\bullet$ & $\circ$ \\
\hline 42 & Prototype quality report & $\circ$ & $\bullet$ & - & $\bullet$ & $\bullet$ & $\circ$ \\
\hline 43 & Quality Assurance Plan & $\circ$ & $\bullet$ & ( & ( & - & $\circ$ \\
\hline 44 & Quality specifications & $\circ$ & - & ○ & $\circ$ & $\circ$ & $\circ$ \\
\hline 45 & Quality testing report & $\circ$ & $\bullet$ & $\bullet$ & $\bullet$ & $\bullet$ & $\circ$ \\
\hline 46 & $\begin{array}{l}\text { Report shared on actual } \\
\text { costs }\end{array}$ & - & $\bullet$ & 0 & ○ & 0 & $\circ$ \\
\hline 47 & Request For Quotation & 0 & $\bullet$ & $\bullet$ & $\circ$ & $\circ$ & $\circ$ \\
\hline 48 & $\begin{array}{l}\text { Requests for New Product } \\
\text { Variants }\end{array}$ & $\boldsymbol{0}$ & $\bullet$ & - & $\circ$ & $\circ$ & ○ \\
\hline 49 & Safety / Norms Approval & 0 & $\bullet$ & ○ & 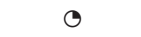 & $\bullet$ & $\circ$ \\
\hline 50 & Sales launch plan & $\bullet$ & - & - & - & - & - \\
\hline 51 & $\begin{array}{l}\text { Specific Process } \\
\text { ldentification }\end{array}$ & \multicolumn{6}{|c|}{ No evidence found } \\
\hline 52 & Standards testing report & $\bullet$ & $\bullet$ & $\odot$ & $\odot$ & $\bullet$ & $\circ$ \\
\hline 53 & Styling requirements & $\circ$ & $\bullet$ & $\circ$ & $\circ$ & $\circ$ & $\circ$ \\
\hline 54 & Supplier control delegation & - & $\bullet$ & $\circ$ & $\circ$ & $\circ$ & $\circ$ \\
\hline 55 & Supplier quality report & $\circ$ & $\bullet$ & - & - & - & $\circ$ \\
\hline 56 & $\begin{array}{l}\text { Tooling Study and } \\
\text { Quotation }\end{array}$ & $\bullet$ & $\bullet$ & - & - & - & $\circ$ \\
\hline 57 & Unit Problem List & $\circ$ & $\bullet$ & $\bullet$ & $\bullet$ & $\bullet$ & $\bullet$ \\
\hline 58 & $\begin{array}{l}\text { Validation of the } \\
\text { Manufacturing } \\
\text { Nomenclatures }\end{array}$ & \multicolumn{6}{|c|}{ No evidence found } \\
\hline 59 & Verification plan & 0 & $\bullet$ & 0 & 0 & $\bullet$ & $\circ$ \\
\hline 60 & Verification report & 0 & - & 0 & 0 & - & o \\
\hline
\end{tabular}

○ No interaction; $\bigcirc$ Low interaction; 9 Medium interaction; $\bullet$ High interaction; $\bullet$ Very high interaction.

The classification of knowledge sharing expressed in the results of this case study follows the intensity levels expressed at Table 2. The results of the knowledge transfer analysis of Company A are depicted in detail at Table 5. In grey box projects, the Scoping phase has a low to medium level of knowledge sharing, with a 1.4 index. During the next phase, build business case, the average knowledge transfer result is 2.9, it means, a medium to high knowledge transfer level. During the Development phase, the average level for knowledge transfer was 2, which is considered low to medium. In the Testing and validation, and Launch phases, the average knowledge transfer was of 1.2 and 1.3, respectively considered low to medium. During the Post-Launch Review, the average knowledge transfer was 0.3 , which is unexpressive. 
Table 5. Analysis of the knowledge transfer in the NPD.

\begin{tabular}{cccccccc}
\hline & & $\begin{array}{c}\text { Phase 1: } \\
\text { Scoping }\end{array}$ & $\begin{array}{c}\text { Phase 2: Build } \\
\text { business case }\end{array}$ & $\begin{array}{c}\text { Phase 3: } \\
\text { Development }\end{array}$ & $\begin{array}{c}\text { Phase 4: } \\
\text { Testing and } \\
\text { validation }\end{array}$ & $\begin{array}{c}\text { Phase 5: } \\
\text { Launch }\end{array}$ & $\begin{array}{c}\text { Post-Launch } \\
\text { Review }\end{array}$ \\
\hline $\begin{array}{c}\text { Knowledge } \\
\text { transfer }\end{array}$ & Sum & 78.0 & 162.0 & 108.0 & 64.0 & 72.0 & 11.0 \\
\hline
\end{tabular}

\subsection{Knowledge translation}

The average knowledge translation between Company $A$ and its supplier in the grey box project, measured in eight situations to avoid sticky knowledge glitches in the NPD suggested by Le Dain \& Merminod (2014), are depicted according to each phase in Table 6 . All the eight situations were found in the study.

The results of the analysis of knowledge translation from the case studied of Company $A$ is presented in Table 7. The table shows that during the initial phase of Scoping the average knowledge translation was 1.9, that is, low to medium. During the second phase Build business case, the average result was 4 , which is represents a very high knowledge translation between two companies. During the following phases Development, Testing and validation, and Launch the average results of knowledge translation levels were low to medium, respectively $1.8 ; 1.5$ and 1.5. Post-Launch Review presented zero knowledge translation during this phase.

Table 6. Analysis of the situations to avoid sticky knowledge glitches in the NPD.

\begin{tabular}{|c|c|c|c|c|c|c|c|}
\hline & $\begin{array}{c}\text { Knowledge translation - Situations to avoid sticky } \\
\text { knowledge glitches during the NPD }\end{array}$ & 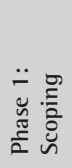 & 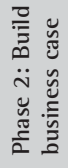 & 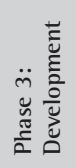 & 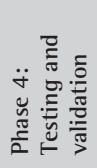 & 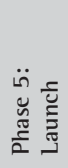 & 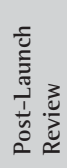 \\
\hline 1 & Contract content & 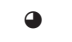 & 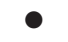 & o & o & o & o \\
\hline 2 & Product Functional \& technical specifications & 0 & - & ( & ० & ० & ० \\
\hline 3 & Quality requirements & ○ & - & ○ & ○ & ○ & ○ \\
\hline 4 & Responsibilities in the project & 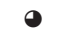 & $\bullet$ & ० & ० & ० & ० \\
\hline 5 & Verification of the prototype & ० & $\bullet$ & ○ & $\bullet$ & ○ & ० \\
\hline 6 & Project planning (due dates) & 0 & ○ & ( & - & ○ & ० \\
\hline 7 & First tool results & $\circ$ & - & - & ○ & - & ० \\
\hline 8 & Logistic requirements integration & 0 & - & ( & (1) & (1) & ○ \\
\hline
\end{tabular}

○ No interaction; Medium interaction; High interaction; $\bullet$ Very high interaction.

Table 7. Analysis of the knowledge translation during the NPD.

\begin{tabular}{|c|c|c|c|c|c|c|c|}
\hline & & 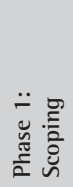 & 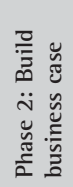 & 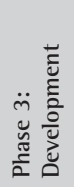 & 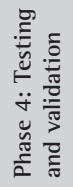 & 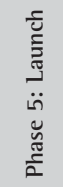 & 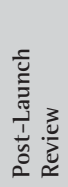 \\
\hline \multirow{2}{*}{ Knowledge translation } & Sum & 15.0 & 32.0 & 14.0 & 12.0 & 12.0 & - \\
\hline & Average & 1.9 & 4.0 & 1.8 & 1.5 & 1.5 & - \\
\hline
\end{tabular}

\subsection{Knowledge transformation}

From the four situations analyzed that were used to measure knowledge transformation proposed by Le Dain \& Merminod (2014) three were observed in the case study of Company A and are presented in more details in Table 8.

During the two initial phases of the NPD, Scoping and Build business case, the average knowledge transformation was medium to high with results of 2 and 2.7 respectively. In the third phase and fourth phase of the NPD, the average knowledge transformation presented average results, 1, that means, not expressive. During the Launch phase, the average knowledge transformation was 2, presenting low to medium levels and in the Post-Launch Review, the result was zero, as seen in Table 9. 
Table 8. Analysis of complex problem-solving situations.

\begin{tabular}{|c|c|c|c|c|c|c|c|}
\hline & $\begin{array}{c}\text { Complex problem solving situations - Knowledge } \\
\text { transformation }\end{array}$ & 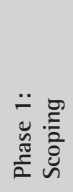 & 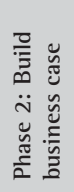 & 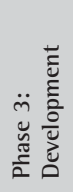 & 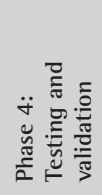 & 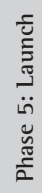 & 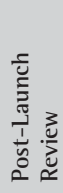 \\
\hline 1 & Elaboration of business model & $\circ$ & $\circ$ & $\circ$ & $\circ$ & $\circ$ & $\circ$ \\
\hline 2 & Acceptability and associated tests & $\bullet$ & $\bullet$ & 0 & 0 & - & $\circ$ \\
\hline 3 & Integration of other department requirements & \multicolumn{6}{|c|}{ No evidence found } \\
\hline 4 & Choice of technical and process solutions & - & • & - & () & () & o \\
\hline
\end{tabular}

Table 9. Analysis of the knowledge transformation in the NPD.

\begin{tabular}{|c|c|c|c|c|c|c|c|}
\hline & & 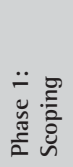 & 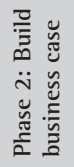 & 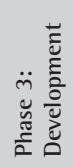 & 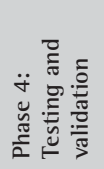 & 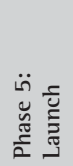 & 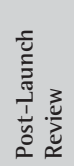 \\
\hline \multirow{2}{*}{ Knowledge transformation } & Sum & 6.0 & 8.0 & 3.0 & 3.0 & 6.0 & - \\
\hline & Average & 2.0 & 2.7 & 1.0 & 1.0 & 2.0 & - \\
\hline
\end{tabular}

\subsection{General panorama of the results}

The average levels of knowledge sharing are presented in Figure 2. The knowledge sharing variation during each NPD phase are depicted in Figure 3.

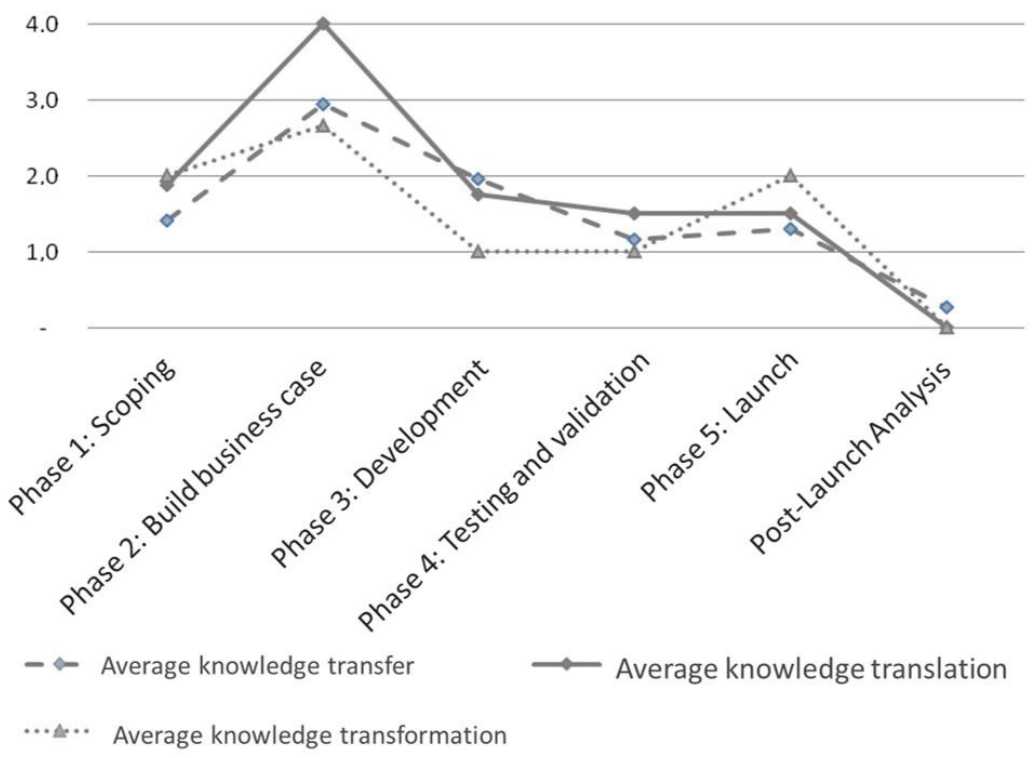

Figure 3. General view of the knowledge sharing intensity in collaborative projects.

\section{Discussions}

As exposed by Petersen et al. (2005), supplier involvement during NPD is important for the success of the project. Le Dain \& Merminod (2014) then, provided a deeper analysis in different collaboration situations for the buyer-supplier relationship. They identified that in grey box projects, knowledge transfer, translation and 
transformation are necessary conditions to the project's progress and the generation of solutions, and that all of these forms of knowledge sharing occur intensively during product development. Comparing with traditional product development projects of the white or black box type, Le Dain \& Merminod (2014) found that a grey box collaborative project, is more intense, however such conclusion does not provide support to engineers, project managers or buyers, in organizing their activities to maximize the NPD results. An isolated analysis does not provide enough information for a professional who wants to start a grey box project to have a clear picture of the specific points of the project where knowledge sharing is most intense.

The analysis of the results expressed in Tables 4 to 8 indicates that in a grey box project, there are phases where there is a higher level of interaction and knowledge sharing and others with lower levels of interaction and knowledge sharing. This information can help professionals in charge of conducting a grey box collaborative project, in a practical way, to know where they should take more care to ensure that the means of communication, such as: documents, contracts, face-to-face meetings or prototype building and assembly are well-designed to ensure the success of the task.

Both Project specialist 1 and Engineer 1 mentioned that the supplier's chief engineer stayed for two whole weeks at Company A and visited, sporadically, the company during prototype building, in order to assist the staff of Company A with questions and also to provide a feedback of the company to the supplier, as a means to provide information of the development process. The same evidence was presented by Le Dain \& Merminod (2014), that mentioned that in one of the companies which used a grey box model, during the co-allocation period, the cooperation between the teams improved and that the supplier was treated as a member of the project team as the company employees. Such collaboration level differentiates conventional product development projects and grey box projects. As the case studied shows, and in others works also highlight, there is a necessity for a specific collaboration, such as the co-allocation in projects of the grey box type, which is a point that demands attention during the NPD.

An important point worth mentioning during the results analysis is the divergence seen between literature and practice on the intensity of knowledge sharing during the Launch Phase. Our case shows that, there is indeed an expressive knowledge sharing during the Product Launch phase, phase 5 of the model of Cooper (1990). Such divergence reinforces the need to find an NPD model that is in line with the specific needs for collaborative developments. This is due to the necessary alignment between theory and practice driving to better results and optimized processes.

As for the theoretical model of the NPD, another specificity of the grey box project is seen. The first and the second phase of the NPD are characterized by a strong interaction and intense knowledge shared with the supplier. Such situation can be observed in Figure 2, with a high level of, basically, all forms of knowledge sharing during the initial phases. This phenomenon shows that, during a collaborative project, feasibility studies are pointless without the active participation of the supplier. The phases of Development (Phase 3) and Testing and validation (Phase 4) presented a synergy between the development of physical prototypes and virtual models. The buyer-supplier knowledge sharing allowed such high accuracy during the development of activities that were usually done during the fourth phase of the project were done during the Development phase.

Also, the data collected during the interviews indicated that a grey box project can have a shorter time of execution than a conventional project. This is possible because the knowledge shared between the organizations is maximized during their collaboration. The most significant time reduction was seen during the Development Phase (Phase 3). This phase is characterized for a significant knowledge translation and transference, which is explained because of the operational nature of the activities performed in this phase. Therefore, to improve the results in this phase, the agents involved in the project must have a high level of interaction at the operational level. Buyer's engineers and purchasers must have open access to the engineers and purchasers of the supplier company in order to make operational decisions faster and right in the first time. This should be a concern of the project team during the Development Phase in a collaborative project.

Regarding the theoretical framework used in this paper, it is important to acknowledge that we adopted Cooper's (1990) stage gates ${ }^{\circledR}$ model, which is one of the most well-known NPD models, but it has been conceived in the product marketing field. Therefore, this model can present some limitations. Other models with an engineering approach have been proposed by Ulrich \& Eppinger (1995) and Wheelwright \& Clark (1992), among others. We followed Cooper's model because it is the most used in the product innovation management literature, the same strong concerned with the knowledge management in product firms, while the other models mentioned before have been used by engineering focused on practical concerns of the NPD. However, while the earlier brings contributions from the initial and end activities, which have more business impacts, the latter contributes for the operations aspects, being more detailed in such phases. Thus, the development phase could be more detailed when other models would have been used in our study. We acknowledge that this is 
a limitation of our study and part of its scope. Our contribution, by using Cooper's model, is that we could provide support to the importance of the business case building stage, which should be strongly focused on knowledge sharing flows when the company aim to develop innovative products with suppliers. This is because the grey box configuration combined with an initial interaction with suppliers can help to reduce significantly the intrinsic risks associated with innovative products (Ayala et al., 2017). This is more important for innovative projects like the one considered in this study, in which the risks related to innovation are higher. We did not consider disruptive innovation projects (Christensen et al., 2015), but the literature on this field has also stressed the importance for collaboration still in the early stages of NPD (Song \& Di Benedetto, 2008). Thus, the initial interaction and knowledge sharing for planning is essential in such cases, as shown in our study. In this sense, our work moved a step forward by showing which knowledge boundaries can help for knowledge sharing in these early stages of NPD when suppliers are involved.

\section{Conclusions}

Our findings showed how knowledge transfer occurs with suppliers alongside the NPD stages, considering specific boundary objects for this aim. We show the intensity of knowledge sharing in each stage, which help to understand the intensities of involvement as well as the ways knowledge is shared. From a theoretical point of view, the results complement previous works that studied knowledge sharing in inter-organizational NPD collaboration. The results of the present study build on the previous results of Le Dain \& Merminod (2014), show that buyer-supplier knowledge sharing in a grey box project does not occur in the same intensity for different boundaries (pragmatic, semantic and syntactic) and more importantly, they do not occur in the same intensity during different product development phases. Therefore, the theoretical contribution of this paper is that it helps to understand the knowledge dynamics with service supplies. We shed light on the roles different knowledge boundaries have in each NPD stages for knowledge sharing in a grey box configuration. Our study also clarifies the importance of knowledge sharing at the the business case stage, as way to strength the project planning and reduce potential NPD risk in the future stages of the NPD process.

On the other hand, from a managerial point of view, the results are useful for practitioners of the new product development field. By clearly presenting how knowledge sharing occurs at each phase of the NPD process, managers can be prepared to this and implements tools to support NPD teams. Since a grey box configuration involves two companies that could have different knowledge management tools and procedures, by knowing deeply knowledge sharing dynamics throughout the NPD process both companies could include this topic in the discussions previous to start the collaboration in order to improve the results of the project. Moreover, managers can follow our findings to understand which practices (knowledge boundaries) they have to reinforce at each stage to assure that knowledge can be better shared with suppliers. Our study also points out that NPD managers must care and pay attention to the earlies stages of NPD for interaction with suppliers. Many practitioners are concerned with the supplier involvement once the project is already defined and need to be executed. However, as we pointed out in this paper, early stages of involvement and knowledge sharing can be important to reduce risks of unsuccess in the NPD process.

Our research has also limitations. First, we used the list of boundary objects in knowledge sharing previously proposed by Le Dain \& Merminod (2014). This list shows an important list of objects related to the business plan phase. Therefore, naturally more knowledge sharing activities were associated to this phase. However, it is important to highlight that since we used a detailed list of boundary objects, this simply reflects the fact that in such face more activities are necessary due to the high risk involved in the planning of a new product. The contribution of our work is showing the variation of knowledge sharing alongside all stages and the level of use of such boundary objects in each phase. In other word, our findings helped us to define which are, in fact, the knowledge boundaries used in each stage. Second, since we used a single case study, the results cannot be generalized. Future works can analyze the same phenomena in more companies or broadly by the application of a survey. Also, the literature broadly states that the knowledge sharing process should be supported by information technologies, especially when NPD teams are geographically separated that is usually the case of inter-organizational project. Then, future studies can concentrate in understanding which information technology tools could be more appropriate to each NPD stage, type of knowledge and intensity level demanded in a grey box configuration. Finally, we considered in this study the NPD of a company in Brazil, where the innovation context suffers several constrains (Frank et al., 2016). Future studies can compare our study to others in developed countries, or even develop new studies in such context, to verify if the knowledge sharing and integration capacity are the same such cases. 


\section{Acknowledgements}

The authors thank the Brazilian National Council for Scientific and Technological Development (CNPq - Conselho Nacional de Desenvolvimento Científico e Tecnológico) (Process n. 305844/2015-6), the Research Council of the State of Rio Grande do Sul (FAPERGS, Fundação de Amparo à Pesquisa do Estado do Rio Grande do Sul) (Process n. 000095-2551/15-2) and the Research Coordination of the Brazilian Ministry of Education (CAPES), for the financial support received to conduct this research.

\section{References}

Alavi, M., \& Leidner, D. E. (2001). Review: knowledge management and knowledge management systems: conceptual foundations and research issues. Management Information Systems Quarterly, 25(1), 107-136. http://dx.doi.org/10.2307/3250961.

Argote, L., \& Ingram, P. (2000). Knowledge transfer: a basis for competitive advantage in firms. Organizational Behavior and Human Decision Processes, 82(1), 150-169. http://dx.doi.org/10.1006/obhd.2000.2893.

Ayala, N. F., Gerstlberger, W., \& Frank, A. G. (2018). Managing servitization in product companies: the moderating role of service suppliers. International Journal of Operations \& Production Management, 1JOPM-08-2017-0484. http://dx.doi.org/10.1108/ 1JOPM-08-2017-0484.

Ayala, N. F., Paslauski, C. A., Ghezzi, A., \& Frank, A. G. (2017). Knowledge sharing dynamics in service suppliers' involvement for servitization of manufacturing companies. International Journal of Production Economics, 193, 538-553. http://dx.doi.org/10.1016/j. ijpe.2017.08.019.

Bodas Freitas, 1. M., \& Fontana, R. (2018). Formalized problem-solving practices and the effects of collaboration with suppliers on a firm's product innovation performance. Journal of Product Innovation Management, 35(4), 565-587. http://dx.doi.org/10.1111/jpim.12432.

Broberg, 0., \& Conceição, C. S. (2017). Learning from participatory design projects across industries. In Proceedings of the 12th International Symposium on Human Factors in Organizational Design and Management (pp. 426-427). Ontario: Association of Canadian Ergonomists.

Büyüközkan, G., \& Arsenyan, J. (2012). Collaborative product development: a literature overview. Production Planning and Control, 23(1), 47-66. http://dx.doi.org/10.1080/09537287.2010.543169.

Carlile, P. R. (2004). Transferring, translating, and transforming: an integrative framework for managing knowledge across boundaries. Organization Science, 15(5), 555-568. http://dx.doi.org/10.1287/orsc.1040.0094.

Christensen, C. M., Raynor, M. E., \& McDonald, R. (2015). What is disruptive innovation. Harvard Business Review, 93(12), 44-53. PMid:17183796.

Cooper, R. G. (1990). Stage-gate systems: a new tool for managing new products. Business Horizons, 33(3), 44-54. http://dx.doi. org/10.1016/0007-6813(90)90040-1.

Cooper, R. G. (1993). Winning at new products: accelerating the process from idea to launch. Boston: Addison-Wesley.

Davenport, T. H., \& Prusak, L. (1998). Working knowledge: how organizations manage what they know. Boston: Harvard Business Press.

Eisenhardt, K. M., \& Graebner, M. E. (2007). Theory building from cases: opportunities and challenges. Academy of Management Journal, 50(1), 25-32. http://dx.doi.org/10.5465/amj.2007.24160888.

Enrique, D. V., Ayala, N. F., Lima, M. J. D. R. F., Marodin, G. A., Gzara, L., \& Frank, A. G. (2018). The use of ICT tools to support collaborative product development activities: evidences from Brazilian industry. Production, 28, e20170099. http://dx.doi. org/10.1590/0103-6513.20170099.

Frank, A. G., \& Ribeiro, J. L. D. (2014). An integrative model for knowledge transfer between new product development project teams. Knowledge Management Research and Practice, 12(2), 215-225. http://dx.doi.org/10.1057/kmrp.2012.57.

Frank, A. G., Ribeiro, J. L. D., Echeveste, M. E., \& ten Caten, C. S. (2013). Relação entre características empresariais e fatores da transferência de conhecimentos entre projetos de produto. Produção, 23(1), 95-106.

Frank, A. G., Cortimiglia, M. N., Ribeiro, J. L. D., \& Oliveira, L. S. (2016). The effect of innovation activities on innovation outputs in the Brazilian industry: market-orientation vs. technology-acquisition strategies. Research Policy, 45(3), 577-592. http://dx.doi. org/10.1016/j.respol.2015.11.011.

Frank, A., \& Echeveste, M. (2012). Knowledge transfer between NPD project teams: a method for the identification of improvement opportunities. International Journal of Quality \& Reliability Management, 29(3), 242-264. http://dx.doi.org/10.1108/02656711211216126.

Frank, A. G., Ribeiro, J. L. D., \& Echeveste, M. E. (2014). Factors influencing knowledge transfer between NPD teams: a taxonomic analysis based on a sociotechnical approach. $R \& D$ Management, 45(1), 1-22. https://doi.org/10.1111/radm.12046.

Gonzalez, R. V. D., \& Martins, M. F. (2015). Gestão do conhecimento: uma análise baseada em fatores contextuais da organização. Production, 25(4), 834-850. http://dx.doi.org/10.1590/0103-6513.145313.

Laursen, L. N., \& Andersen, P. H. (2016). Supplier involvement in NPD: a quasi-experiment at Unilever. Industrial Marketing Management, 58, 162-171. http://dx.doi.org/10.1016/j.indmarman.2016.05.023.

Le Dain, M. A., \& Merminod, V. (2014). A knowledge sharing framework for black, grey and white box supplier configurations in new product development. Technovation, 34(11), 688-701. http://dx.doi.org/10.1016/j.technovation.2014.09.005.

Nonaka, 1., \& Takeuchi, H. (1995). The knowledge creation company: how Japanese companies create the dynamics of innovation. Oxford: Oxford University Press.

Petersen, K. J., Handfield, R. B., \& Ragatz, G. L. (2005). Supplier integration into new product development: coordinating product, process and supply chain design. Journal of Operations Management, 23(3-4), 371-388. http://dx.doi.org/10.1016/j.jom.2004.07.009.

Polanyi, M. (1962). Personal knowledge: towards a post-critical philosophy. Boca Raton: Routledge. 
Ramadhan, F., \& Samadhi, T. M. A. A. (2016, December). Inter-organizational trust and knowledge sharing model between manufacturer and supplier in the automotive industry. In IEEE International Conference on Industrial Engineering and Engineering Management (IEEM) (pp. 856-860). USA: IEEE. http://dx.doi.org/10.1109/1EEM.2016.7797998.

Samuel, K. E., Goury, M. L., Gunasekaran, A., \& Spalanzani, A. (2011). Knowledge management in supply chain: An empirical study from France. The Journal of Strategic Information Systems, 20(3), 283-306. http://dx.doi.org/10.1016/j.jsis.2010.11.001.

Sinkovics, R. R., Kuivalainen, O., \& Roath, A. S. (2018). Value co-creation in an outsourcing arrangement between manufacturers and third party logistics providers: resource commitment, innovation and collaboration. Journal of Business and lndustrial Marketing, 33(4), 563-573. http://dx.doi.org/10.1108/JBIM-03-2017-0082.

Song, M., \& Di Benedetto, C. A. (2008). Supplier's involvement and success of radical new product development in new ventures. Journal of Operations Management, 26(1), 1-22. http://dx.doi.org/10.1016/j.jom.2007.06.001.

Ulrich, K. T., \& Eppinger, S. D. (1995). Product design and development. USA: McGraw-Hill Higher Education.

Voss, C., Tsikriktsis, N., \& Frohlich, M. (2002). Case research in operations management. International Journal of Operations \& Production Management, 22(2), 195-219. http://dx.doi.org/10.1108/01443570210414329.

Wheelwright, S. C., \& Clark, K. B. (1992). Revolutionizing product development: quantum leaps in speed, efficiency, and quality. New York: Simon and Schuster.

Yoo, S. H., Shin, H., \& Park, M. S. (2015). New product development and the effect of supplier involvement. Omega, 51, 107-120. http://dx.doi.org/10.1016/j.omega.2014.09.005. 